AIAA-98-0819

\title{
THE RESTORATION OF A WWII AVENGER PROVIDES PROJECTS FOR WPI STUDENTS
}

\author{
Professor Emeritus Donald N. Zwiep \\ Professor and Associate Provost William W. Durgin \\ Associate Fellow \\ Worcester Polytechnic Institute \\ Worcester, MA 01609 \\ Mr. Nathan H. Mayo \\ Mayocraft, Inc. \\ Bolton, MA 01740
}

\begin{abstract}
$\underline{\text { Abstract }}$
In 1970 WPI completely revised its traditional approach to engineering education. The resulting program, the WPI Plan, emphasized the use of projects as a distinctive process for achieving educational goals. Every student, as a degree requirement, had to successfully complete two major projects: one in a student's major field, the Major Qualifying Project (MQP) and the second, the Interactive Qualifying Project (IQP), which related science and technology to societal issues.
\end{abstract}

The IQP's related to the restoration of the WWII Avenger at Mayocraft, Inc. for the Collings Foundation in Stow, Massachusetts enabled the students working with the authors as advisors to apply classroom learning to real world problems including the effects of WWII technology on society over the last half century. Issues ranging from the location of an aircraft for restoration, costs, location or manufacture of parts, collection and verification of data, and whether the final project should be a flying or static display were among the many factors evaluated by the student project teams and incorporated into their final oral and written reports. Although not a part of the projects of the students it is of interest that the Avenger is flying and its restoration project has been made known to the public via the Discovery Channel.

Post project analysis includes student evaluation of the program and faculty as well as periodic reviews of the IQP's by faculty committees. Abstracts of the projects are published. Continuous evaluation of all IQP's makes sure they integrate into a physical reality the

Copyright () 1998 by the American Institute of Aeronautics and Astronautics, Inc. All rights reserved. social, political, and humanistic dimensions of a technical world.

\section{$\underline{\text { Objective }}$}

This paper will describe the IQP process of the WPI students in association with the restoration of the Avenger. Recommendations for continued IQP restoration projects, including program evaluation, are discussed.

\section{Introduction}

Since 1908 when the late Robert H. Goddard graduated from WPI the college has been involved, in varying degrees, with aeronautical activities. Since 1926 the Mechanical Engineering Department has enabled its students to pursue programs in aeronautics and aerospace. Project activities with emphasis on both application and theory have always been a fundamental part of the programs. Since 1970, the required projects, $\mathrm{MQP}$ and $\mathrm{IQP}$, have provided unique curricular flexibility with the opportunity for students and faculty to select projects and involve themselves with offcampus resources such as people with expertise in the field, industrial or governmental organizations interested in the potential results of the study, and educational institutions with similar interests, for example. This paper resulted from the IQP's carried out by several teams of WPI students working through the Collings Foundation of Stow, Massachusetts and with the off-campus advising of Mr. Nate Mayo and the oncampus direction of Professors Durgin and Zwiep. While projects evolve in many different ways, a common denominator is the personal relationship of the advisors. In this instance, each of the advisors is a licensed pilot with a personal interest in WWII aircraft. This paper will limit itself to IQP activities only. 


\section{The Interactive Qualifying Project}

The objective of the IQP is to have WPI graduates be cognizant, as practicing professionals in their field, of how their careers will affect the global society of which they are a part. The project is normally carried out in the junior year with teams of three to five students. Oral and written reports are required and given special emphasis. Off-campus IQP activities, WPI currently has 18 overseas project sites in addition to its many domestic locations are encouraged. This paper resulted from off-campus activities about 35 miles from WPI, convenient driving distance.

\section{Project Development}

The IQP, a required educational experience for each student at WPI, provides an unlimited range of possible projects. Individuals or groups select projects of interest and importance to them. Professional and technical competence necessary to solve distinctive problems invites the students to utilize open-ended approaches in its solution. Projects generally lead to additional undertakings in the same field. There are also serendipitous effects. There are no unique answers.

An IQP may originate with students, faculty, or with external agencies and are directed to solving real problems faced by business, industry, government, educational, and social agencies. The basic elements of a project include the definition of the problem, the student team, the advisors, and the resources needed and available. Project support from external sources is encouraged but must follow WPI's inviolate rule, "credit, no pay - pay, no credit." A typical arrangement is for an agency to pay all direct costs associated with a project plus a stipend to the WPI Projects Center. Sponsoring agencies are well informed that the final reports are those of the students, not of faculty consultants.

To aid students in developing ideas for projects WPI through its Projects Center maintains for review by students and faculty a Completed Project Listing, and arranges meetings with Project Coordinators in the academic departments, members of the Interdisciplinary Studies Division, and the Projects Office staff. A continuing discussion between students planning projects and those who have finished projects takes place informally. A college-wide Project Planning Day normally takes place in April. A special Projects Fair for students wishing to complete an IQP at an overseas location is held in October. Regardless of discipline, any faculty member may be an IQP advisor. For students planning to complete an IQP overseas a Preliminary Qualifying Project (PQP) is mandatory. The $\mathrm{PQP}$ is encouraged for all students. Written and oral reports of a professional quality are mandatory. When appropriate, video and audiotapes may be part of the reporting process. The WPI Writing Resources Center is available for the improvement of writing skills in line with the WPI emphasis on presentations such as proposals, formal written documents, term papers, and abstracts associated with projects.

The IQP advisor who must be a WPI faculty member is responsible for the grade of each student on a project through the "Completion of Degree Requirement" form. The reports of sponsored projects are normally distributed within the agency. Abstracts of IQP's are published annually in INTERACTIONS. All IQP's are catalogued for reference in the WPI Library and retained for five years.

Off-campus insurance and legal agreements for students, faculty, and sponsoring organizations are normally handled through the WPI Projects office. Housing, financial arrangements with sponsors, and the use of proprietary data are examples.

\section{$\underline{\text { Initial Planning }}$}

As soon as the general subject area for a project(s) has been determined an academic operational plan is developed. Students must be recruited and project teams established, specific project topics and objectives announced, and, when appropriate, students enrolled in a Prequalifying Project (PQP). If the project involves full or part time off-campus work direct costs, transportation, housing, communications, and medical services, for example, must also be considered.

\section{$\underline{\text { Support }}$}

WPI projects enjoy varying degrees of financial support. Typically, sponsors identify projects and provide the finances needed to complete them. Project support is arranged through the Projects Center and may include a stipend covering the entire project, $\$ 5,000$ is a normal amount, or an agreement to cover out-of-pocket expenses, work space, and costs such as mailing, information searches, local travel, computer usage, and similar costs authorized by the sponsor. Students are not allowed direct monetary support. Sponsor concerns such as confidentiality and proprietary information must be resolved prior to the start of the project. WPI safeguards are in place to alleviate such concerns. 


\section{Identification and Selection of Projects}

The selection of the project and the determination of its objective is critical for both the students and advisors. In the Avenger projects, questions dealing with relevancy to technology and society issues were paramount for an underlying theme was identifying the technological breakthroughs which then resulted in a better society in later years. Limiting the scope of the project so that it was realistic for the equivalent of seven weeks of full time study by the student teams was often very difficult as was collecting information, military and civilian, about the Avenger during its operational time which was 50 years ago. The results for the students was an oral history from people who flew the Avenger coupled with logistical data from manufacturers, historical references, museums, governmental archives, and similar sources.

\section{Typical IOP's with Social Technological Relationships Related to the Restoration of the Avenger}

1. Restoration of a Grumman WWII Avenger-A team of students working at WPI and Mayocraft, Inc. developed the history of the particular airplane and were involved in the actual restoration of a number of parts of the airplane. They came to understand the societal need for the identification and development of technologies and the result of those technologies on the outcome of WWII.

2. Air Crew Fatigue-Two students, working at WPI, examined and evaluated existing literature and, combined interviews with known experts, identified concerns and developed recommendations for reducing fatigue related safety problems for airline air crews.

3. Preserving the Past-A three-student project dealing with the historical factors of the restoration of WWII airplanes. The project report made a detailed study of static, museum type displays versus the advantage of a flying model, a living museum.

4. International Symposium on Material Deterioration-Two student teams setup the mechanics of an international symposium dealing with the corrosion of materials associated with aircraft restoration. While the symposium did not take place when the IQP's were finished in 1994, it could take place whenever funding becomes available.

5. Aircraft Restoration-A three person IQP dealing with aircraft restoration with emphasis on the Grumman Avenger of the Collings Foundation of Stow, Massachusetts. Included in this IQP were reviews of potential aircraft and their location as well as discussion on challenges the restorers of WWII aircraft are facing.

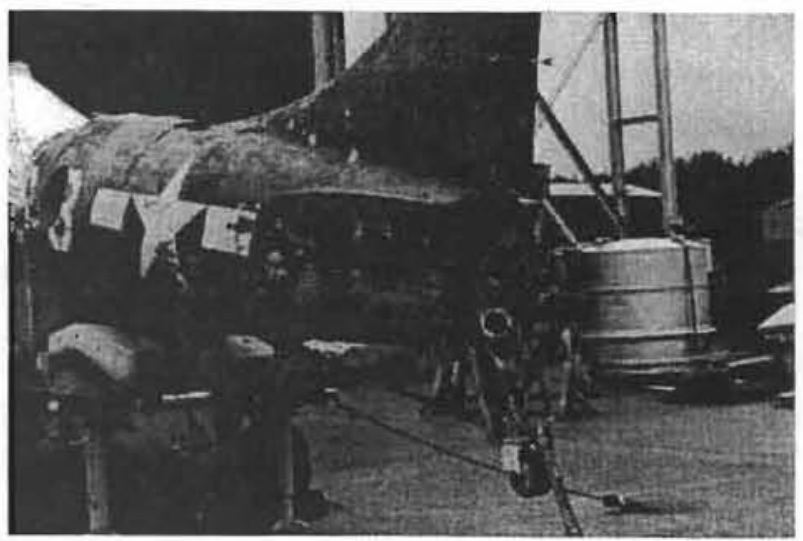

In addition to meeting the general requirements of an IQP at WPI several historical factors surfaced. For example, the amplidyne systems previously used in steel mills were redesigned for use in driving the ball turret on the Avenger, the first such system of WWII aircraft. The use of the radar altimeter was one of the first applications for a single engine, all weather aircraft, in hunting submarines, and its use has continued to virtually all aircraft today. The corrosion of aluminum and other metallic parts and the restoration process has developed into a continuing technical challenge. An indirect benefit to WPI engineering students is that the project approach and its quantifiable activities appear to be exactly what was desired in the ABET Criteria 2000.

\section{The Restored Avenger}

The photographs show the Avenger in varying conditions of renovation from the breakdown of its components to its readiness for flight test. A video of the restoration process at Mayocraft, Inc. was made by the Discovery Channel and has been shown on television to national audiences.

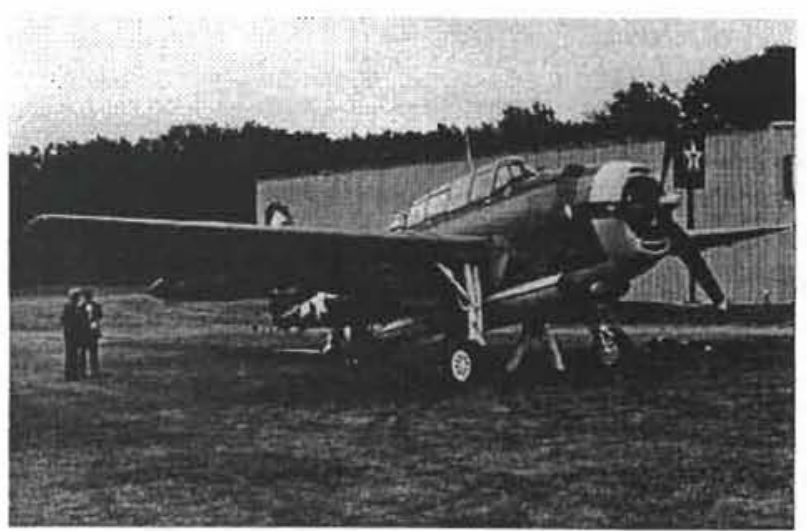




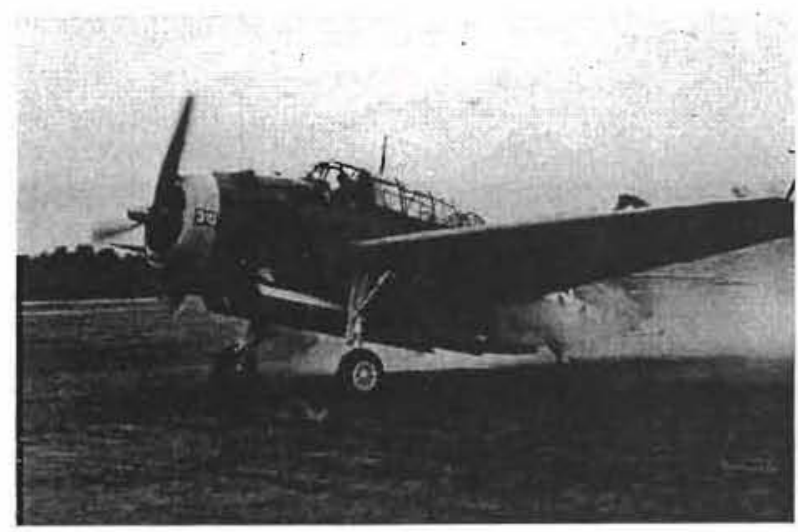

\section{Quality Control and Evaluation}

The IQP advisors work closely with student project teams; a WPI faculty member is responsible for the final grade. On most occasions the advisors, coadvising is highly encouraged and for the Avenger projects included someone not associated with WPI, become initially involved because the project is related to their own expertise and interests, including hobbies. Evaluation of the IQP includes continuous grading of the oral and written reports of the students(s) by the advisor and a bi-annual peer review of all IQP's by a faculty team. The team is selected to cover the entire range of IQP topics from Technology and the Environment to Law and Technology. Experienced project advisors are mentors to new advisors. Prior IQP experience is mandatory for anyone involved with overseas projects.

\section{$\underline{\text { Post Project Activities }}$}

All IQP's are catalogued for reference in the WPI library for five years and then returned to the advisor(s). The reports of an IQP completed during off-campus activities are distributed within the concerned agency. Abstracts of all IQP's are published in the Project Center document INTERACTIONS and made available to an extensive off-campus mailing list.

Advisors nominate meritorious IQP's for the President's IQP Awards which includes a certificate of merit and an honorarium. Abstracts of IQP's are often published in the professional literature, local newspapers, and WPI documents. Student discussions of an IQP with a recruiter have been a highly beneficial procedure during job placement interviews.

The restoration of the Avenger has concluded, for now, student projects. Mayocraft, Inc. is in the planning stage of completely fabricating a Curtiss 503-C, Seagull. If their proposal is successful there will be many additional student projects.

\section{Conclusion}

1. The projects involving the WPI students and faculty with the renovation of the WWII Avenger were an unqualified success from both an educational and cultural vantagepoint.

2. The closeness of the workshop where the renovation took place coupled with an opportunity for the students to have a limited hands-on experience with the professional restorers was critical to the success of the program.

3. The historical and cultural benefits of the restoration projects were extremely beneficial to students and faculty. The opportunity for the students to interact with many persons who were actually involved with Avenger aircraft in WWII was a distinctive experience that may not be repeatable.

4. Papers authored by students and/or faculty have resulted from these projects.

5. If the project were to be carried out in seven weeks of full time activity of the students, a minimum time requirement of WPI, the same results could not have been accomplished. IQP's of this type must be spread out over a long calendar time, at least six months.

6. The projects associated with the renovation of the Avenger could not have been successfully carried out without the cooperation and support of Nathan Mayo of Mayocraft, Inc. and the Collings Foundation, owner of the Avenger.

7. Student evaluations consistently reported the project experience with which they were involved was a major highlight of their undergraduate educational experiences at WPI.

\section{Acknowledgment}

Without the cooperation, understanding, and help of Mr. Nathan Mayo who directed the renovation activities on the Avenger of the Collings Foundation the degree of success attained by the students on their projects would just not have been possible.

\section{Selected References}

This is not a bibliography. Rather, it notes sources to which specific reference could be made as well as sources where help was less tangible.

1. THE WPI PROJECTS PROGRAM, WPI Projects Center, 1994.

2. THE CHRISTIAN SCIENCE MONITOR, Boston, Massachusetts, "Today the Classroom, Tomorrow the World", March 7, 1994.

3. ASEE PRIZM, "Globalizing Engineering Education", April, 1995. 
4. ZWIEP AND MASSIE, "Educating Engineering Students for a Global Social Responsibility”, 1995 World Conference on Engineering Education, Oct. 1520, 1995, St. Paul Minnesota.

5. MASSIE AND ZWIEP, "Pragmatic International Exchange of Students", ASEE Annual Conference, June, 1995.

6. AVENGER PILOTS HANDBOOK, U.S. Gov't Printing Office, 1944.

7. AVENGER MAINTENANCE MANUAL, U.S. Gov't Printing Office, 1944.

8. RESTORATION OF THE AVENGER, The Popular Mechanics Show, The Discovery Channel, November, 1995.

9. RESTORATION OF WWII AIRPLANES, The Smithsonian Institution, Oral and Written Communications, 1996.

10. WEBSTER, Aviation Historian, P.O. Box 37, Shannock, RI 02875, Oral and Written Communications, 1994-5.

11. Sport Aviation, Experimental Aircraft Association, P.O. Box 3086, Oshkosh, WI 54903-3086, December, 1996.

12. TBM/TBF Avenger in Action, Charles L. Scrivner, Squadron/Signal Publications, Inc., 1115 Crowley Drive, Carrollton, TX 75011-5010. 